\title{
Split hand/split foot deformity and LADD syndrome in a family: overlap between the EEC and LADD syndromes
}

Didier Lacombe, Françoise Serville, Dominique Marchand, Jacques Battin

\begin{abstract}
A mother and daughter are reported with apparently dissimilar syndromes. The mother has a split hand/split foot deformity and the daughter a condition consistent with a diagnosis of LADD syndrome. Absence of clefting and deficient formation of saliva and tears are the main signs that differentiate the LADD from the EEC syndrome. However, no distinct feature is constant between these two autosomal dominant disorders that show great phenotypic variability. This report emphasises the overlap between the LADD and the EEC syndromes. (f Med Genet 1993;30:700-3)
\end{abstract}

The lacrimo-auriculo-dento-digital (LADD) syndrome is an autosomal dominant disorder characterised by hypoplasia or aplasia of the lacrimal and salivary tract, dysplastic ears with cup shaped pinnae, sensorineural deafness, dental abnormalities, and limb defects predominantly on the radial border of the hands. Renal abnormalities have also been documented. The ectrodactyly-ectodermal dysplasia-clefting (EEC) syndrome is another autosomal dominant condition with great variability in expression and penetrance. Absent lacrimal puncta, conductive hearing loss, deformed ears, and dental abnormalities have also been documented in the EEC syndrome, leading Hennekam ${ }^{1}$ to suggest that the same pleiotropic gene could cause the LADD syndrome and the EEC syndrome and that these two syndromes are extremes of the same autosomal dominant condition. We report on a family with ectrodactyly and LADD syndrome that emphasises the overlap between these two disorders.

\section{Case reports}

CASE 1

The proband, a Caucasian female, was referred to the Genetic Clinic because of poor growth and mental retardation. She was born at term after an uneventful pregnancy and delivery. Birth weight was $2500 \mathrm{~g}$, length $45 \mathrm{~cm}$, and head circumference (OFC) $31 \mathrm{~cm}$. Motor development was delayed from birth. She was treated for bilaterally dislocated hips.

At 22 months, weight $(6600 \mathrm{~g})$, height $(71 \mathrm{~cm})$, and OFC $(42.5 \mathrm{~cm})$ were below the 3rd centile. Psychomotor development was severely delayed. She had no speech and was rated at an 8 month old level on the TermannMerill scale. On examination, the ears were bilaterally low set, posteriorly rotated, and small with downward folded helices (fig 1). The deciduous teeth were poorly implanted with hypoplastic lower incisors and canines and peg shaped upper lateral incisors (fig 2). The child exhibited minor facial dysmorphic features including a bulbous nasal tip and flared nostrils. Clinical examination and his-

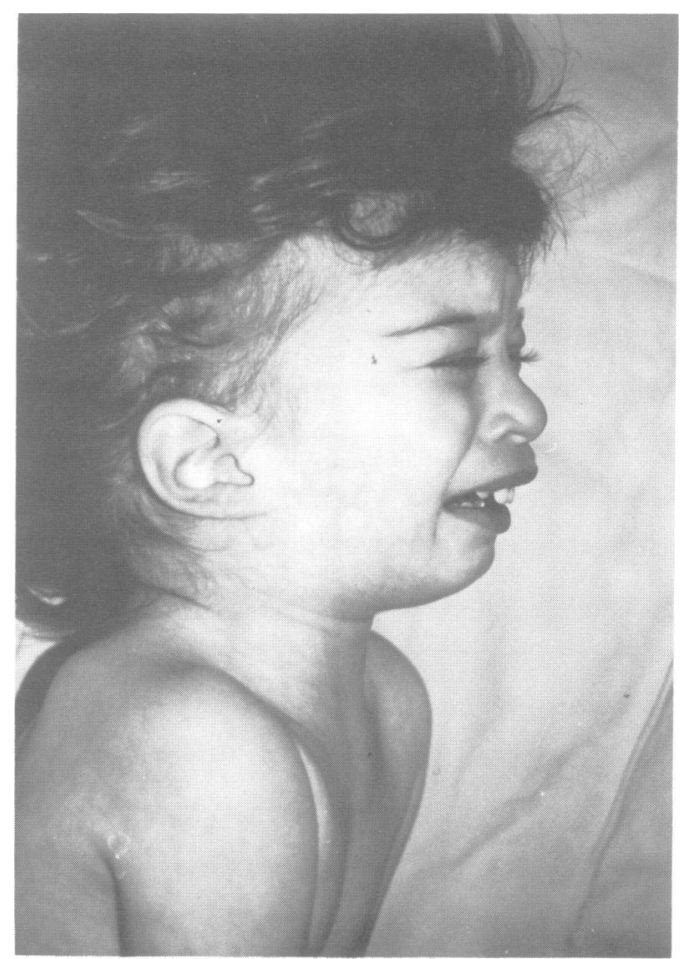

Figure 1 Case 1, side view. Note low set and posteriorly rotated ears and bulbous nasal tip.

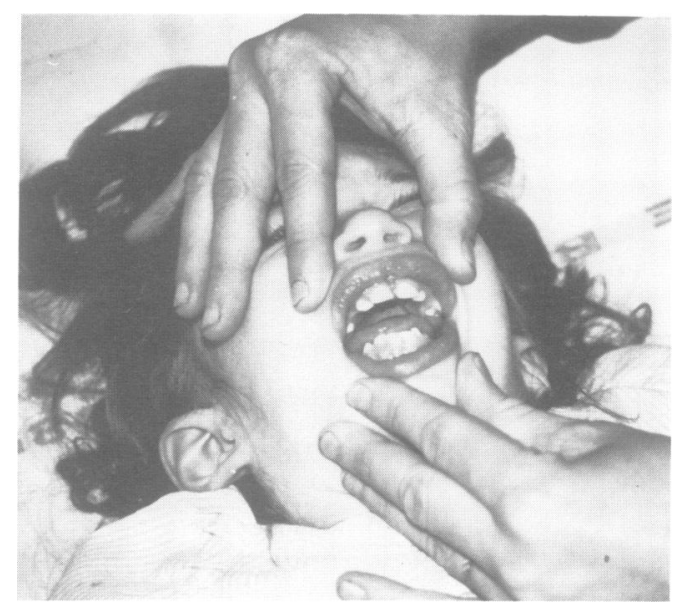

Figure 2 Poor implantation of deciduous teeth of case 1. 

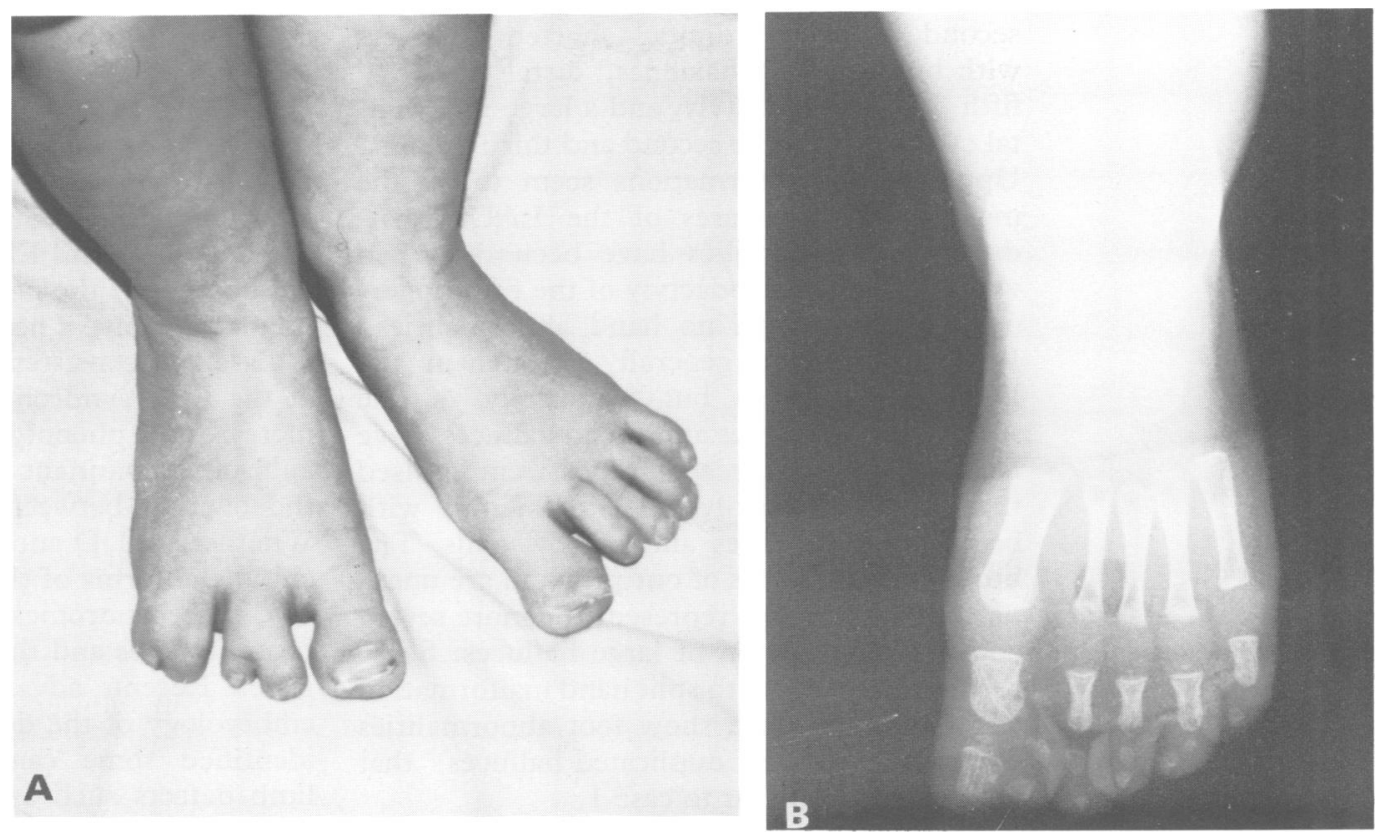

Figure 3 (A) Feet of case 1 showing partial duplication of the big toes and syndactyly between the left 2nd and 3rd toes and 4th and 5th toes. (B) $X$ ray examination of the right foot showing duplication of the hallux.

tory showed recurrent dacryocystitis and a chronic, mild, purulent eye discharge, mainly after sleep. The child had poor lacrimation and the lacrimal puncta were hypoplastic. Scalp hair was sparse and brittle. The palate, skin, and nails were normal. The hands were normal apart from slightly low implantation of the thumbs. Examination of the feet showed soft tissue syndactyly of the left second and third and fourth and fifth toes (fig 3A), with large big toes that were partially duplicated on $x$ ray examination (fig 3B). She had stereotyped and psychotic behaviour. Auditory brainstem evoked potentials and audiogram indicated bilateral sensorineural hearing loss, with no recognisable reaction up to $70 \mathrm{~dB}$. Urine analysis, renal ultrasound, CT scan of the brain, and fundus examination were normal. Chromosome analysis was normal $46, \mathrm{XX}$. Metabolic screening showed no abnormalities. The maxillary deciduous right second molar is missing at 30 months of age.

\section{CASE 2}

The mother of case 1 was 25 years old and had typical split foot deformity of both feet (fig 4) and severe malformations of the upper limbs with two ulnar digits on each hand. Radiologi-

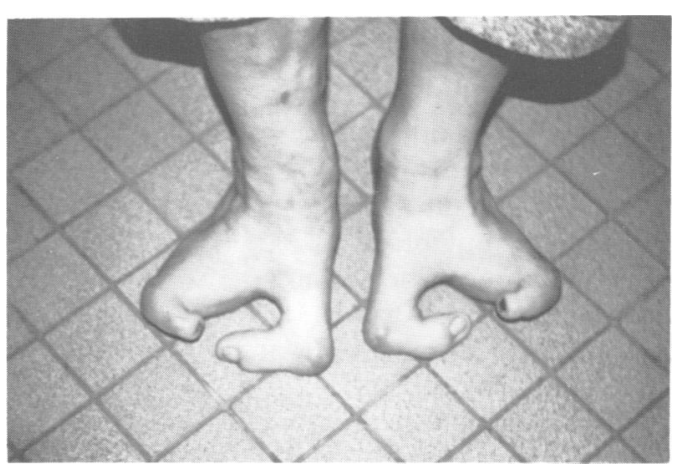

Figure 4 Bilaterial split foot of case 2. cal examination showed three metacarpals on the right hand and four metacarpals and a hypoplastic first phalanx of the third digit on the left hand (fig 5). She had no skin or hair abnormalities or oral clefting. Poor tooth implantation had been corrected. The ears were not dysplastic and she did not have any hearing or lacrimation difficulties. Karyotype was normal $46, \mathrm{XX}$.

She had only one child (case 1). Her two brothers and one sister were reported not to have any features of LADD syndrome or abnormalities of the extremities. The father of the proband was normal on examination.

\section{Discussion}

The proband had the lacrimal, auricular, and dental abnormalities of the LADD syndrome. She had broad bifid halluces and syndactyly of the toes with minimal upper limb involvement. Radial ray defects in the upper limbs are well documented in the LADD syndrome, including bifid, finger-like, or hypoplastic thumb, and hypoplasia of the thenar eminence. ${ }^{2}$ Various other digital abnormalities have been reported, such as syndactyly of the

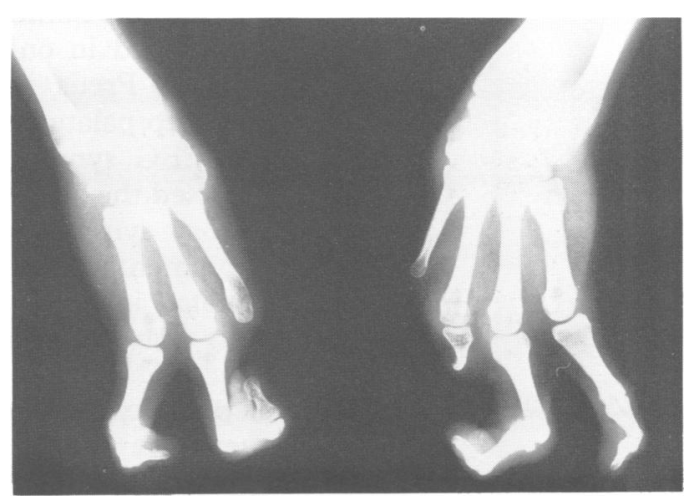

Figure $5 X$ ray examination of the hands of case 2 showing the radial finger defects. 
second and third digits, ${ }^{3}$ shortened fingers with broad distal phalanges, ${ }^{1}$ distal tapering, ${ }^{4}$ fifth finger clinodactyly, and a large interdigital cleft between the second and third fingers. ${ }^{3}$ Upper limb malformations seem to be the most variable features of the LADD syndrome. Some families have been described with only mild clinodactyly of the fifth fingers on $x$ ray, ${ }^{5}$ or with no hand abnormalities. ${ }^{6}$ Lower limbs are generally normal in the LADD syndrome, but syndactyly of the second and third toes and broad halluces ${ }^{1}$ have been reported. A recent report ${ }^{4}$ emphasised the lower limb involvement in a family with broad, large halluces and narrow nails. The broad, bifid halluces of our proband are unexpected, but seem to represent the more severe end of the spectrum of large halluces. Some reported patients with split hand malformation and EEC syndrome show foot abnormalities (syndactyly of toes, duplicated halluces) ${ }^{7}$ that are strikingly similar to case 1 .

Robinson et al described a family in which the proband had malformed ears, bilateral deafness, hypodontia and peg shaped incisors, a short middle finger on one hand, bilateral syndactyly of the third and fourth fingers, and bilateral absence of the middle phalanges of the feet, suggesting a diagnosis of LADD syndrome. However, his two great uncles had a split foot deformity and cleft lip and palate, and his mother had syndactyly of the hands and feet, cleft lip and palate, hypodontia, and conductive hearing loss, so the authors concluded that this family had EEC syndrome and hearing loss. This family and our report, show overlap between the EEC and LADD syndromes. Temtamy and $\mathrm{McKusick}^{7}$ had already reported great variability in the familial transmission of abnormalities of the extremities in the EEC syndrome, ranging from mild camptodactyly of the fifth fingers to split hand/split foot deformity in the same family in association with absent helix. Wiegmann and Walker ${ }^{9}$ described a family with chronic dacryocystitis, absence or early loss of teeth, and split hand/split foot without other ectodermal abnormalities or clefts.

About $90 \%$ of patients with EEC syndrome have absent lacrimal puncta and about $30 \%$ have conductive hearing loss. ${ }^{2}$ Congenitally missing permanent teeth, coniform teeth, and enamel dysplasia are common. All features of the LADD syndrome have been described in EEC syndrome families, but cleft lip palate has been reported in only $75 \%$ of cases of EEC syndrome. ${ }^{2}$ Preus and Fraser ${ }^{10}$ have argued that cleft lip/palate may not be an essential part of the EEC syndrome. Küster et $a l^{11}$ have emphasised the fact that ectrodactyly is not an obligatory symptom of the EEC syndrome. Hypopigmentation of the skin and hair has been noted in most white patients, but black patients have normal pigmentation. Chranowska et $a l^{12}$ have recently emphasised the great phenotypic variability in the EEC syndrome: none of the affected members of this family had the same pattern of abnormalities. Genitourinary malformations are documented in the LADD syndrome ${ }^{34}$ and in at least $20 \%$ of cases of EEC syndrome. ${ }^{2}$ Microcephaly and mental retardation have been reported in about $10 \%$ of cases of the EEC syndrome, but not in the LADD syndrome. The mental status of case 1 could have worsened because of the failure to treat the deafness. Early recognition of the LADD and EEC syndromes is important because of the possibility that the affected infant may have a hearing disorder.

Case 2 is consistent with partial expression of the EEC syndrome. The family described increases the phenotypic variation in these two autosomal dominant disorders and emphasises the overlap between these two syndromes. Whether LADD and EEC syndromes represent allelic forms of the same gene or contiguous gene syndromes will have to be left to future studies and the mapping of a potential gene. Recent advances in the molecular embryology of the developing limb bud have identified some candidate morphogens for limb defects such as retinoid metabolism or receptors. ${ }^{13}$ Six cases of interstitial 7(q21 or 22) deletions ${ }^{1314}$ and four cases of apparently balanced chromosomal rearrangements with breakpoints at 7(q21 or 22), ${ }^{15}$ each exhibiting ectrodactyly (and sometimes additional features of the EEC syndrome), suggest a locus in $7 \mathrm{q} 22$ near to the proximal interface for limb differentiation. On the other hand, there are 17 additional deletions involving this band but not associated with ectrodactyly. ${ }^{13}$ Genetic interactions such as position effect and unmasking heterozygosity, and extreme variability in the expression of ectrodactyly could explain this discrepancy. Qumsiyeh ${ }^{17}$ believes that the critical region for the EEC syndrome is at 7q11.2-q21.3. The breakpoints reported in the different deletions or translocations can be determined by using the alphoid sequences available for chromosome 7 . DNA analysis now offers the prospect of identifying the gene. Linkage analysis of families with genetically inherited limb defects (EEC or LADD syndromes) will provide answers concerning genetic heterogeneity.

1 Hennekam RCM. LADD syndrome: a distinct entity? Eur $\mathfrak{f}$ Pediatr 1987;146:94-5.

2 Gorlin RJ, Cohen MM Jr, Levin LS. Syndromes of the head and neck, 3rd ed. Oxford: Oxford University Press, 1990:716-19, 868-9.

3 Hollister DW, Klein SH, De Jager HJ, Lachman RS, Rimoin DL. The lacrimo-auriculo-dento-digital syndrome. F Pediatr 1973;83:438-44.

4 Bamforth JS, Kaurah P. Lacrimo-auriculo-dento-digital syndrome: evidence for lower limb involvement and 1992;43:932-7.

5 Thompson E, Pembrey M, Graham JM. Phenotypic variation in LADD syndrome. $\mathcal{F}$ Med Genet $1985 ; 22: 382-5$.

6 Wiedemann HR, Drescher J. LADD syndrome: report of new cases and review of the clinical spectrum. Eur $\mathcal{f}$ new cases and review of

7 Temtamy S, McKusick V. The genetics of hand malformations. Birth Defects 1978; XIV(3):53-71.

8 Robinson GC, Wildervanck LS, Chiang TP. Ectrodactyly, ectodermal dysplasia, and cleft lip-palate syndrome. $\mathscr{f}$ Pediatr 1973;82:107-9.

9 Wiegmann OA, Walker FA. The syndrome of lobster claw deformity and nasolacrimal obstruction. $f$ Pediatr Ophthalmol 1970;7:79-85.

10 Preus M, Fraser FC. The lobster claw defect with ectodermal defects, cleft lip-palate, tear duct anomaly and renal anomalies. Clin Genet 1973;4:369-75.

11 Küster W, Majewski F, Meinecke P. EEC syndrome without ectrodactyly? Clin Genet 1985;28:130-5.

12 Chranowska KH, Krajewska-Walasek M, Rump Z, Wis niewski L, Fryns JP. Anodontia as the sole clinical sign of the ectrodactyly-ectodermal dysplasia-cleft lip (EEC) syndrome. Genet Counsel 1990;1:67-73.

13 Winter RM, Tickle C. Syndactylies and polydactylies: 
embryological overview and suggested classification. Eur f Hum Genet 1993;1:96-104.

14 Rivera H, Sanchez-Corona J, Burgos-Fuentes VR, Melendez-Ruiz MJ. Deletion of $7 \mathrm{q} 22$ and ectrodactyly. Genet Counsel 1991;2:27-31.

15 Roberts SH, Hughes HE, Davies SJ, Meredith AL. Bilateral split hand and split foot malformation in a boy with a de novo interstitial deletion of 7q21.3. 7 Med Genet 1991;28:479-81.
16 Neri G, Genuardi M, Pomponi MG, Sammito V, Zollino $M$. Further evidence for the presence of a split hand/foot deformity gene on chromosome $7 \mathrm{q} 21$ from a family segregating a 2;7 translocation. Am 8 Hum Genet 1992;51:A85. 17 Qumsiyeh MB. EEC syndrome (ectrodactyly, ectodermal dysplasia and cleft lip/palate) is on 7q11.2-q21.3. Clin Genet 1992;42:101. 